\title{
Research on Creative Entry Point of Modern Graphic Design
}

\author{
Huijuan Chang \\ Huanghe Science and Technology College \\ Zhengzhou, China
}

\begin{abstract}
With reform and development of new material, new thought and new media, the pattern of manifestation and type of modern graphic design become more and more complicated and diversified. But it cannot be denied that in numerous works or cases of graphic design, the phenomenon of plagiarism among them, which become a common failing of design. Therefore, looking for creative point of graphic design has become difficult point that many designers try every means to obtain. This article starts with looking for way to enter the creative point of graphic design to discuss the importance of originality on graphic design.
\end{abstract}

Keywords—graphic design; originality; way; entry point

\section{INTRODUCTION}

Graphic design mainly includes two aspects: One is the technology related to graphic design. The other is originality of graphic design, especially creativity and inspiration, which are the key to decide the quality of graphic design works. The design of Apple products is unique, leads the trend and becomes prevailing custom for people to purchase. It has close relationship with innovation and originality of design team of Apple products. Therefore, it is the core content that is the most difficult and attracts the most attention of designers to look for the entry point of the best originality when designing works. Putting forward distinctive design angle can highlight design personality of designers, characteristics of design works and greatly promote its artistic appeal and impact. So to speak, in graphic design industry, to be the champion, it is necessary to start with originality. This industry has reached a consensus about it.

\section{ANALYSIS ON CONCEPT OF MODERN GRAPHIC DESIGN AND SIGNIFICANCE OF ORIGINALITY}

\section{A. Analysis on Concept of Modern Graphic Design}

The so-called modern graphic design brings audiences visual impact through images or stereo pictures. It is formed by a number of elements such as originality, graphics, words, color and composition of pictures. It provides people with novel, unique, comfortable, impressive, fashionable and classical design effects through permutation and combination of different elements. Graphic design has become common language of designers and essential tool for merchants to attract customers and shape brand image. Modern graphic design has turned into technical work to create huge commercial value. The success of Apple Inc shows that the commercial value created and produced by design industry is enormous.

\section{B. Analysis on Significance of Originality of Modern Graphic Design}

The reason why modern graphic design can have huge commercial value is that it has unique style in design effects. Adopting machine-made design methods, it obviously cannot follow the regular of commercial value that a thing is valued if it is rare, let alone producing appealing artistic charm. Originality is the most effective way to change this situation. The idea of modern graphic design has made the conception originality independent of graphic design and become basis and core of graphic design. An excellent design work can emerge at the right moment with inspiration and originality of designers.

It is undeniable that the technology of graphic design is also very important. Originality is the soul. Technology is the important way to make the soul understood or recognized by people. Graphic design technology better manifests initial inspiration of designers through flexibly dealing with color, words, graphics and other elements. This kind of works can better embody the style and idea of designers. The key point that audiences pay attention to graphic design works is design idea and originality. It is the most important that whether the design work can surprise audiences. At this time, the technology of graphic design can be ignored for common audience. The soul, namely originality of the work decides whether works of designers can spread and become fashion and classics. This shows that originality is the prerequisite and important standard for the success of graphic design works.

\section{ANALYSIS ON WAY TO LOOK FOR ENTRY POINT OF GRAPHIC DESIGN ORIGINALITY}

Modern graphic design becomes increasingly complicated and moves towards the direction of diversified development. The entry point of graphic design originality should start with elements of graphic design, but originality brought by different changes of these elements will completely change. Meanwhile, design objective, profound understanding for national culture and flexible application of design tools can become entry point of originality. Now I will research the way of entry point of modern graphic design originality from four aspects. 


\section{A. Analysis on Creative Entry Point of Component Elements in Graphic Design}

Component elements of graphic design mainly include three core parts, namely words, graphics and color. Different combination and changes of the three elements can convey creative ideas of designers to audiences. Therefore, the three component elements become the most direct and effective way for designers to pursue originality.

1) Creative entry point of words: Words are very important design elements and include two parts, namely font shape and language description of words. Generally speaking, terse and forceful language words always can accurately convey theme and concept of design works. Extremely creative font design can freely show unique design style of designers. The composing of words can embody unique understanding of designers on design works as well. Therefore, the design element of words can leave designers many creative excavation spaces. It is worth us to better discuss it.

2) Creative entry point of graphics: Graphics include geometric figures and other irregular figures. It is common language in design field. Graphics can let design works more visualized and direct. For example, cartoon works use exaggerated graphics to show humorous and ironic meaning. It is more sharp and wonderful than directly using literal expression as well as easier for audiences to understand. Another extreme should be paid attention to when seeking for creative entry point in graphic elements. It refers to that many designers excessively pursue novelty and odd, even deviate from design philosophy. Creative entry point of graphics attaches more importance to combination of novelty and standard, using rich changes to attract people.

3) Creative entry point of color: In graphic design works, color is the first design element that attracts people's attention. It is well-known that the director Zhang Yimou shows his own ingenuity in use of color in films. No matter in Ambush on all Sides or Heroes, many frames can be captured to become posters of deliberate design. Color of reasonable application and match of color become eye-popper and give people very comfortable visual perception, even directly influence emotion and imagination of people. It is embodied in many web designs. For example, the background color of some webpage takes thin shade as the main style. The words of the main body also adopt thin shade. It is unpleasant and difficult for audiences to look at and read the words and easy to cause visual fatigue. This shows that the match, selection and reasonable application of color need continuous adjustment, originality and innovation to become comfortable and natural for audiences to look at. Meanwhile, it helps audiences to better understand design philosophy of designers. From this point, color can completely become the entry point of originality.

\section{B. Look for Way of Creative Entry Point through Design Objectives}

When designing works, designers often take user requirements, market positioning, design capability of them as design objectives and finally create a complete work. It is most obviously embodied in commercial graphic design. It is also the key for designers to look for creative point. However, compared with creative entry point of design elements, it is obviously more difficult to seek for creative entry point in design objectives.

This is because the originality of designers shall base on market positioning, user requirement and design capacity of them to uniformly consider and discuss. For example, it will change unceasingly according to user requirements, which are often popular and cannot bring creative inspiration for designers on design. At this time, it requires designers to extract according to general requirements and design works that can meet design requirements as well as lead the trend. Besides, it is the consideration for element of design level. Many designers may think of very good originality but often cannot realize it because of design capacity, so creative entry point shall base on design capacity. For market positioning, designers should consider more factors, such as dynamic changes of the market, design philosophy of the same kind of products, information collection of related designs, then extract and sublimate to form unique creative design philosophy. In general, it is a big challenge for each designer to complete this process. This shows that it is more difficult to seek creative entry point on design objectives, but the works will achieve great success if it is succeeded.

\section{Profound Comprehension of National Culture Is the Important Way of Creative Entry Point}

Each nation has its own culture, behavior pattern, delight of life and values. Meanwhile, what belongs to the nation belongs to the world. Reasonably applying national culture to design works is the common creative entry point of graphic design. The Yellow Earth directed by Chen Kaige is landmark work. The success of this work originates from profound reflection of national culture in the northwest. Each filmscreenshot has deep stigma of national culture, which makes this film succeed. What's more, many graphic design works of our country adopt red and yellow as the main colors, which is the application of national culture in reality. Nowadays, the originality of this color has been very common. But in festive occasions, it is eternal color.

Of course, if integrating traditional Chinese ink painting in graphic design, it will produce shocked design effects, which has been fully embodied in design works of Mr. Kan Taikeung. In many design works, he adopts the composition idea of round heaven and square earth and large area of white space and let design style of Chinese ink painting run through it to form design works with profound national culture connotation. Therefore, it can appeal to audiences with originality of designers and reach outstanding actual effects. 
It is the basic skill of designers to grasp design tools. From the initial freehand sketching to printing to computer generation and camera shooting, graphic design develops very fast. It puts forward higher requirements for graphic designers to grasp the skill. As time goes by, designers mastering design tools more flexibly. It is found that mixed application of different design tools will always produce different design effects, so design tools can become creative entry point of designers as well. In some animation or cartoon works, mixed use of freehand sketching and computer drawing can make the effect of composition more beautiful and better convey design originality of designers. Besides, post production of camera shooting works through using computers can further strengthen design effects.

With more flexible mastering of design tools, especially graphic design technology on computer, and because computer can cancel improper originality through revocation, instead of elaborate thinking, when seeking creative entry point, many designers randomly seek originality through scrawling. It cannot promote design level of designers. On the contrary, it will make them lazy. As time passes, it reduces the ability of originality and innovation of designers. Therefore, only through reasonably using design tools can designers better seek creative entry point.

\section{CONCLUSION}

The entry point of originality summarized by this article cannot represent or cover all aspects of modern graphic design. It plays the role of offering a few commonplace remarks by way of introduction so that other may come up with valuable opinions at most. Besides, as time goes by, the design concept also changes ceaselessly. Just as the cycle of fashion in clothing industry, maybe antiquated design concept and creative style will be popular again, but the entry point of originality still remain essentially the same despite all apparent changes. Only through seriously starting from four aspects of composition elements, design objectives, national culture and design tools can we make design works of designers win support among people and lead fashion.

\section{REFERENCES}

[1] Liu Bin. Research of Chinese Characters on Decorative Application in Graphic Design [J], Modern Decoration (Theory), the 3rd issue in 2011.

[2] Ma Pengcheng, Li Bin. Interpretation on Originality of Experience Form in Graphic Design [J], Western Forum, the 12th issue in 2010.

[3] Su Zhuan. Application of Chinese Ink Painting Culture in Modern Graphic Design $[\mathrm{J}]$, Theory and Practice of Contemporary Education, the 5 th issue in 2010.

[4] Liu Peng. Discussion on Influence of Chinese Traditional Aesthetic Taste on Modern Graphic Design [J], Art Education, the 6th issue in 2009.

[5] Tang Hong. Simplicity and Elegance in Harmony-Thinking on Meaning of Modern Graphic Design [J], Art Panorama, the 4th issue in 2010 . 